\title{
A TWO-COMPONENT PRODUCTION INVENTORY-ASSEMBLY SYSTEM
}

\author{
V.S.S. Yadavalli \\ Department of Industrial and Systems Engineering \\ University of Pretoria, South Africa \\ sarma.yadavalli@up.ac.za
}

\begin{abstract}
The paper considers a two-component continuous review inventory system where one of two components is produced by the organisation and the other is supplied by an outside supplier. The two components are assembled into an end product. There are two different product types. Demand occurs according to a Poisson process for each of the product types. It is assumed that product 1 is produced and its production time is arbitrarily distributed. Production is interrupted when the inventory level of product 1 reaches its maximum level. Replenishment of product 2 is done according to an adjustable reorder policy, and the lead-time follows an exponential distribution. Identifying the stochastic process as a semi-regenerative process, steady-state measures such as mean stationary rate of the number of demands lost, mean number of demands satisfied, mean number of replenishments made, are found. The total unutilised capacity of the production system is found, and a cost analysis is also studied. A numerical example is provided to illustrate the results obtained.
\end{abstract}

\section{OPSOMMING}

' $n$ Voorraadsisteem wat kontinu hersien word vir twee verskillende komponenttipes word bestudeer. Die komponente word gebruik vir twee verskillende produktipes. Die verbruik van elke produktipe word beskryf deur 'n Poissonverdeling. Die produksietyd vir produktipe 1 is arbitrêr verdeel. Sodra die voorraadpeil van produk 1 die maksimum bereik, word produksie gestaak. Aanvulling van produktipe 2 word gedoen volgens ' $n$ verstelbare herbestelbeleid met eksponensiele leityd. Identifisering van die stogastiese proses as half-regenererend lei vervolgens tot bepaling van gestadigde maatstawe soos gemiddelde aantal verlore eenhede, gemiddelde bevredigde vraag, en gemiddelde aantal aanvullings. Die totale ledigheid van die sisteem word bepaal en die gepaardgaande koste bereken. 'n Syfervoorbeeld word voorgehou om die resultate te bevestig. 


\section{INTRODUCTION}

There are many organisations that manufacture some or all of the subcomponents of the assembly system they are dealing with. For example, in an automotive industry a car manufacturer needs chassis, steering, wheels, etc. to assemble a car. Some of the components, like tyres and electric bulbs, may be outsourced, while components like the engine, the chassis, etc. may be manufactured by the organisation itself. Not only must the inventory of outsourced components be controlled, but also the inventory of the different components that are self-manufactured. Further, the production system that is used to manufacture these components may also be subject to failure and repair. Arreola-Risa (1996) considered a multi-item production-inventory system, and obtained optimal base stock levels when the unit manufacturing times are either determinate or exponential.

Bourland et al (1996) studied a timely demand information model. According to this model, two factories use a standard periodic base-stock policy for one particular item, but the equal-length production cycles of the two factories do not necessarily coincide. A similar study was done by Arbib and Marinelli (2004) for a glass industry, using the 0-1 linear programming formulation based on the p-model. However, attention has not been paid so far in the literature to the continuous review of inventory systems (Raafat [1991], Yadavalli et al [2004]) where good control of the production process is required to maintain the inventory of the manufactured components. To fill the gap, an attempt is made in this paper to study a model of a two-component-assembly system in which one component is outsourced and the other is manufactured by the organisation itself, with the assumption that the lifetime of the production system is an arbitrarily distributed random variable and that the system can be repaired after failure.

The organisation of the paper is as follows:

In section 2 the model, with its assumptions and the notation used in the paper, is presented. The auxiliary functions needed to derive the inventory level distribution are obtained in section 3. The inventory level distribution is discussed in section 4 , and the limiting distribution of the inventory level is obtained in section 5 . The system performance measures are found in section 6 . In section 7 , a numerical illustration is given to illustrate the results obtained.

\section{THE MODEL ASSUMPTIONS AND NOTATION}

Consider a two-component-assembly system in which one component is outsourced and the other is manufactured by the organisation itself. To be specific, let the component manufactured by the organisation itself be called "component 1", and the outsourced one “component 2 ". 


\section{Assumptions:}

1. The production time of component 1 is an arbitrary random variable with p.d.f. $g()$, c.d.f.G(.) and survivor function $\bar{G}($.$) .$

2. The life-time of the production system of component 1 is exponential with parameter $\alpha$, and its repair time has an arbitrary distribution with p.d.f. $g_{r}($.

3. If the production system fails during the course of the production of a unit of component 1 , the production starts afresh after completion of repair. After production completion, component 1 goes directly to the inventory.

4. The maximum inventory level of component 1 is $S_{1}$.

5. When the inventory level of component 1 reaches the maximum level, the production is stopped; it restarts when a demand for the end-product is satisfied. During the production stoppage period, the production system cannot fail.

6. The maximum inventory level of component 2 is $S_{2}$ and it is reordered when its inventory level reaches $s_{2}$, and is replenished according to an adjustable reordering policy. The lead-time is assumed to be exponentially distributed with parameter $\mu$.

7. The demands for the end-products occur according to a Poisson process with parameter $\lambda$.

8. On the occurrence of a demand, the two components are instantly assembled and the demand is met. Even if one component is out of stock, the demand is lost and is not back-logged.

\section{Notation:}

$L_{i}(t)$ : The inventory level of the product $i$ at any time $t, \quad t \geq 0, i=1,2$.

$X(t)=\left(L_{1}(t), L_{2}(t)\right)$, the vector process representing the state of the system at time $t$.

$R_{i}: \quad$ Event that a reorder is placed for product $i, i=1,2$.

$\ell$ : $\quad$ Event that a demand is lost.

$d: \quad$ Event that a demand is satisfied.

$b: \quad$ Event that the production system fails.

$N_{\eta}\left(t_{1}, t_{2}\right)$ : Random variable representing the number of $\eta$ - events that have occurred in the interval $\left(t_{1} \cdot t_{2}\right]$, where $\eta$ can be any one of the types $R_{i}, \ell, d, b . N_{\eta}(t)=N_{\eta}(0 . t)$

$E_{0}$ : $\quad$ Event that denotes the initial condition that the production for product 1 commences and the inventory level of product 2 is 0 . 


\section{AUXILIARY FUNCTION}

Consider the inventory system component 2 as a single product inventory system that has the function $\mu e^{-\mu t}$ as the p. d. f. of the lead-time, and is replenished according to an adjustable reorder policy. We define

$$
\varphi(i, j, k, t)=\operatorname{Pr}\left[L_{2}(t)=j, N_{d}(t)=k \mid L_{2}(0)=i\right] \text {. }
$$

We restrict the usage of this function to the period of production of a unit of component 1 or to the period of repair time of the production system.

Accordingly, to derive an expression for $\varphi(i, j, k, t)$, we consider the following cases separately:

\section{Case 1:}

$0 \leq i \leq s_{2}$

Using probabilistic arguments, we have:

$$
\begin{aligned}
& \varphi(i, j, k, t)=\lambda e^{-(\lambda+\mu) t} \odot \\
& \varphi(i-1, j, k-1, t)+\mu e^{-(\lambda+\mu) t} @ \varphi\left(S_{2}, j, k, t\right), i>0, k>1 ; \\
& \varphi(0, j, k, t)=\mu e^{-u t} \Subset \varphi\left(S_{2}, j, k, t\right), k>0 \\
& \varphi(i, i, 0, t)=e^{-(\lambda+\mu) t}, i>0 \\
& \varphi(0,0,0, t)=e^{-\mu t} \\
& \varphi\left(0, S_{2}, 0, t\right)=e^{-\lambda t}\left(1-e^{-\mu t}\right)
\end{aligned}
$$

\section{Case 2:}

$i>S_{2}$

$\varphi(i, j, k, t)=\lambda e^{-\lambda t} \subseteq j(i-1 . j, k-1 . t), k>0$.

$\varphi(i, i, 0, t)=e^{-\lambda t}$

\section{INVENTORY LEVEL}

Let $0=T_{0}, T_{1}, T_{2}, \ldots \ldots$ denote the successive time points at which the production of a unit of component 1 is started, and let $X_{n}=X\left(T_{n}+\right), n=0,1,2, \ldots$. be the inventory level of the system at $T_{n}$. Then $(X, T)=\left\{\left(X_{n}, T_{n}\right): n=0,1,2 \ldots ..\right\}$ is a Markov renewal process with state space

$$
E=\left\{(i, j) \mid i=0,1,2, \ldots, S_{1}, \ldots \ldots S_{1} ; j=0,1,2, \ldots, S_{2}, \ldots, S_{2}\right\}
$$


The semi-Markov kernel $Q(i, j, t \mid l, m)$ of this process (see Cinlar [1975]) is the family of probabilities defined by

$Q(i, j, t \mid l, m)=\operatorname{Pr}\left\{X_{n+1}=(i, j), T_{n+1}-T_{n} \leq t \mid X_{n}=(l, m)\right\}$,

where $(i, j),(l, m) \in E$. We write

$Q(i, j, d t \mid l, m)=\operatorname{Pr}\left\{X_{n+1}=(i, j), t<T_{n+1}-T_{n}<t+d t \mid X_{n}=(l, m)\right\}$.

To derive an expression for the function $Q$ we observe the following:

(i) Some of the epochs $T_{n}$ are also epochs of production completion. In such

(ii) cases, $L_{1}\left(T_{n}+\right)>0$.

Since $T_{n+1}$ is an epoch of production commencement, the production of a unit that commenced at the epoch $T_{n}$ is completed at $T_{n+1}$ or the production systems fails in $\left(T_{n}, T_{n+1}\right)$ and the repair is completed at $T_{n+1}$.

The inventory level of product 1 can reach the state $S_{1}-1$ at $T_{n+1}+$ in the following ways:

$L_{1}\left(T_{n}+\right)=S_{1}-2$ and the production then commenced is completed at $T_{n+1}$ and no demand is satisfied in $\left(T_{n}, T_{n+1}\right)$.

a. $\quad L_{1}\left(T_{n}+\right)=S_{1}-1$ and the production system fails, and this repair is completed at $T_{n+1}$ and no demand is satisfied in $\left(T_{n}, T_{n+1}\right)$.

b. $\quad L_{1}\left(T_{n}+\right)=S_{1}-1$, the production then commenced is completed prior to $T_{n+1}$, say in $(u, u+d u) \cdot u<T_{n+1}$ and the production is stopped at $u$ and the first demand after the stoppage of production occurs at $T_{n+1}$.

We have the following cases for $j, m=0,1,2, \ldots \ldots, S_{2}$ :

\section{Case 1:}

$l=0, i=0$

Since $i=0$, we note that

(i) The epoch $T_{n+1}$ cannot synchronise with production completion.

(ii) No demand can be satisfied. 
Hence we have:

$$
Q(0, j, t \mid 0, m)=\int_{0}^{t}\left\{a^{-a u} \bar{G}(u) \subseteq g_{r}(u)\right\} j(m, j, 0, u) d u \text {. }
$$

\section{Case 2:}

$l=0, i>0$

$Q(i, j, t \mid 0, m)=\int_{0}^{t} g(u) e^{-a u}(m, j, 0, u) d u$.

\section{Case 3:}

$0<l \leq S_{1}-1, i=0$

As in case 1, the epoch $T_{n+1}$ cannot be an epoch of production completion.

Accordingly we have:

$Q(0, j, t \mid l, m)=\int_{0}^{t}\left\{\alpha e^{-a u} \bar{G}(u) @ g_{r}(u)\right\} \varphi(m, j, l, u) d u$.

\section{Case 4:}

$0<l \leq S_{1}-2,0<i \leq S_{1}-1$

$Q(i, j, t \mid l, m)=\left[e^{-a t} g(t) j(m, j, l-i+1, t)+\left\{a e^{-a t} \bar{G}(t) \subset g_{r}(t)\right\} j(m, j, l-i, t)\right] H(l-i)$

$+e^{-\alpha t} g(t) \varphi(m, j, 0, t) \delta_{i, l+1}$.

Where $H($.$) is a Heaviside function and d_{i j}$ is a Kronecker's delta function.

\section{Case 5:}

$l=S_{1}-1, i=S_{1}-1$

$Q\left(S_{1}-1, j, t \mid S_{1}-1, m\right)=H(j-1)\left\{e^{-\alpha t} g(t) \subseteq \lambda e^{-\lambda t}\right\} \varphi(m, j .0, t)$

$+e^{-a t} g(t) \phi(m, j, l, t)+\left\{\alpha e^{-a t} \bar{G}(t)\right\} \varphi(m, j, 0, t)$.

The semi-Markov kernel of $(X, T)$ is the matrix $Q(t)=[Q(i, j, t \mid l, m)]$ 
and is of order $\left(S_{1}+1\right)\left(S_{2}+1\right) \times\left(S_{1}+1\right)\left(S_{2}+1\right)$.

Next we define the Markov renewal function of $(X, T)$ as

$R(i, j, t \mid l, m)=\sum_{n=0}^{\infty} Q^{(n)}(i, j, t \mid l, m)$

The Markov renewal kernel of $(X, T)$ is the matrix $\overline{\boldsymbol{R}}(t)=[R(i, j, t \mid l, m)]$.

From the theory of Markov renewal processes, we have $\boldsymbol{R}^{*}(s)=\left[I-Q^{*}(s)\right]^{-1}$.

To study the distribution of the inventory level, we consider the vector process

$X(t)=\left(L_{1}(t), L_{2}(t)\right), t \geq 0$.

This process is a semi-regenerative process on the set $E$. It is clear the Markov renewal process $(X, T)$ is embedded in $Z(t)$ (see Cinlar [1975]).

Define for any $(i, j),(l, m) \in E$,

$$
\begin{aligned}
& P(i, j, t \mid l, m)=\operatorname{Pr}\left\{X(t)=(i, j) \mid X_{0}=(l, m)\right\} \\
& K(i, j, t \mid l, m)=\operatorname{Pr}\left\{X(t)=(i, j), T_{1}>t \mid X_{0}=(l, m)\right\} .
\end{aligned}
$$

The $K$ function describes the behaviour of the inventory level at any time $t<T_{1}$. Using probabilistic arguments, we have the following cases:

\section{Case 1:}

$l=0$

$$
K(i, j, t \mid 0, m)=\left\{1-\delta_{i, 1}\right\}\left[\bar{G}(t) e^{-\alpha t}+\alpha e^{-\alpha t} \bar{G}(t) \odot \bar{G}_{r}(t)\right] \varphi(m, j, 0, t)
$$

\section{Case 2:}

$0<l \leq S_{1}-1, i=0$

$$
K(0, j, t \mid l, m)=\left[\bar{G}(t) e^{-\alpha t}+\alpha e^{-\alpha t} \bar{G}(t) \Subset \bar{G}_{r}(t)\right] \varphi(m, j, l, t)
$$

\section{Case 3:}

$0<l \leq S_{1}-2,0<i \leq S_{1}-1$ 
$K(i, j, t \mid l, m)\left[\bar{G}(t) e^{-a t} j(m, j, l-i+1, t)+\left\{a e^{-a t} \bar{G}(t) \odot \bar{G}_{r}(t)\right\} j(m, j, l-i, t)\right] H(l-i)$

\section{Case 4:}

$l=S_{1}-1, i=S_{1}-1$

$K\left(S_{1}-1, j, t \mid S_{1}-1, m\right)=\bar{G}(t) e^{-\alpha t} \varphi(m, j, 0, t)+\left\{\alpha e^{-\alpha t} \bar{G}(t) \odot \bar{G}_{r}(t)\right\} \varphi(m, j, 0, t)$

\section{Case 5:}

$i=S_{1}, l=S_{1}-1$

$K\left(S_{1}, j, t \mid S_{1}-1, m\right)=\left\{e^{-a t} g(t) \odot e^{-l t} j(m, j, 0, t)\right\}$

Next, to obtain an expression for $P(i, j, t \mid l, m)$ we condition on $T_{1}$ and use the regenerative property of $X(t)$ to write

$$
P(i, j, t \mid t, m)=K(i, j, t \mid l, m)=\sum_{\left(i_{1}, j_{1}\right) \in E} \int_{0}^{t} Q\left(i_{1}, j_{1}, d u \mid l, m\right) P\left(i, j, t-u \mid i_{1}, j_{1}\right)
$$

The above equation is a Markov renewal equation, the solution of which is given by

$$
P(i, j, t \mid l, m)=\sum_{\left(i_{1}, j_{1}\right) \in E} \int_{0}^{t} R\left(i_{1}, j_{1}, d u \mid l, m\right) K\left(i, j, t-u \mid i_{1}, j_{1}\right)
$$

\section{THE LIMITING DISTRIBUTION OF THE INVENTORY LEVEL}

Consider the imbedded Markov chain $X_{n}=\left(L_{1}\left(T_{n}+\right), L_{2}\left(T_{n}+\right)\right)$. Let the stationary distribution of the Markov chain $X_{n}$ be

$$
\bar{\pi}=\left\{(0,0),(0,1),(0,2), \ldots \ldots,\left(s_{1}, s_{2}\right),\left(s_{1}, s_{2}+1\right), \ldots .,\left(S_{1}-1, S_{2}\right)\right\}
$$

Solving the matrix equation $\quad \bar{\pi} \dot{Q}=\bar{\pi}$ along with the normalizing condition

$$
\bar{\pi} \dot{\boldsymbol{e}}=1 \text { we obtain } \bar{\pi} \text {. }
$$

Next, we consider the mean sojourn time $m(i, j)$ of the Markov renewal process $(X, T)$ in the state $(i, j)$. It is defined by 
$m(i, j)=E\left[T_{n+1}-T_{n} \mid X_{n}=(l, m)\right]$

where $(l, m) \in E$. Using the theory of Markov renewal process, we have:

$m(i, j)=\int_{0}^{\infty}\left[1-\sum_{(i, j) \in E} Q(i, j, t \mid l, m)\right] d t$.

Now we define $P(i, j)=\lim _{t-\infty} P(i, j, t \mid l, m)$, where $(i, j) \in E$. Then, by a theorem of semi-regenerative processes, we have:

$P(i, j)=\frac{\sum_{(l, m) \in E} P(l, m) \int_{0}^{\infty} K(i, j, t \mid l, m) d t}{\bar{\pi} \cdot \bar{m}}$

The above equation gives the limiting distribution of the inventory level.

\section{MEASURES OF SYSTEM PERFORMANCE}

The performance of the system can best be studied by considering the measures such as the mean number of reorders for product 2 , the mean number of lost demands, and the mean number of times the system goes for repair. To obtain these measures, we require the corresponding first-order product density

$h_{\eta}(t)=\lim _{\Delta \rightarrow 0} \operatorname{Pr}\left\{N_{\eta}(t, t+\Delta) \geq 1 \mid E_{0}\right\} / \Delta$

where $\eta$ is any one of the various events of the system. Then the mean number of $\eta$-events occurring in the interval $(0, t]$ is given by

$E\left[N_{\eta}(t)\right]=\int_{0}^{t} h_{\eta}(u) d u$

and the stationary mean-rate of $\eta$-events by

$E\left[N_{\eta}\right]=\lim _{t \rightarrow \infty} \frac{1}{t} E\left[N_{\eta}(t)\right]=\lim _{t \rightarrow \infty} h_{\eta}(t)$

\subsection{Mean stationary rate of replenishments for product 1}

Since a replenishment can occur only when the inventory level of product $1 \leq s_{1}$, and that the lead-time rate is $\mu$, the mean-stationary rate of product 1 is given by

$E R 1=\lim _{t \rightarrow \infty} h_{R_{1}}(t)=\sum_{i=0}^{s_{1}} \sum_{j} P(i, j) \mu$. 


\subsection{Mean stationary rate of reorders for product 2}

Since a reorder for product 2 can only be made when a demand is satisfied and the inventory level of product 2 reaches $s_{2}$, we have the mean-stationary rate of reorder for product 2 given by

$$
E R 2=\lim _{t \rightarrow \infty} h_{R_{2}}(t)=\sum_{i=1}^{S_{1}} P\left(i, s_{2}+1\right) \lambda
$$

\subsection{Mean-stationary rate of lost demands}

$$
E\left[N_{\ell}\right]=\lim _{t-\infty} h_{\ell}(t)\left\{\sum_{j} P(0, j)+\sum_{i}(i, 0)\right\} \lambda \text {. }
$$

\subsection{Mean-stationary rate of repair of production system:}

$$
E(r)=\lim _{t \rightarrow \infty} h_{r}(t)=\lim _{t \rightarrow \infty} R(i, j, t \mid l, m) \Subset \alpha e^{-\alpha t} \bar{G}(t)=\frac{\alpha \bar{G}^{*}(\alpha)}{\bar{\pi} \cdot \bar{m}}
$$

The following measures are also useful in the study of the system performance.

\subsection{Total unutilized capacity}

If $A(t)$ be defined by $A(t)=\operatorname{Pr} \quad\left\{\right.$ the production system is idle at time $\left.t \mid E_{0}\right\}$. Then the mean-fraction of unutilized time of the production system is given by

$$
\lim _{t \rightarrow \infty} A(t)=\sum_{j=0}^{S_{2}} P\left(S_{1}, j\right)
$$

\subsection{Total repair time}

If $B(t)$ denotes the probability that the production system is under repair at time $t$, then the mean-stationary rate of the repair-time is given by

$$
\begin{aligned}
& \lim _{t \rightarrow \infty} \frac{1}{t} \int_{0}^{t} B(u) d u=\lim _{t \rightarrow \infty} B(t)=\lim _{t \rightarrow \infty} R(i, j, t \mid l, m) \subseteq \alpha e^{-\alpha t} \bar{G}_{r}(t) \\
& =\frac{a \bar{G}^{*}(a) \bar{G}_{r}^{*}(a)}{\bar{p} \cdot \bar{m}}
\end{aligned}
$$

\subsection{Numerical illustration}

Assuming $g(t)=a e^{-a t}, g_{r}(t)=b e^{-b t}$, and considering the following values for the parameters: $\lambda=4.00, \mu=50.00, \alpha=0.005, \mathrm{a}=0.0001, \mathrm{~b}=10.0, \mathrm{~S}_{1}=5, \mathrm{~S}_{2}=4, \mathrm{~s}_{1}=$ $3, s_{2}=3$, we present in Tables 1 to 5 the values of the mean-stationary rate of (i) the reorder for the product 2 (ER2), (ii) the lost demands (EL) (iii) repair production systems (ERP), and (iv) total repair time TRPT (using the equations (24)-(30)). 


\begin{tabular}{rcrrr}
\hline$\lambda$ & ER2 & EL & \multicolumn{1}{c}{ ERP } & \multicolumn{1}{c}{ TRPT } \\
\hline 4.000000 & 3.918395 & 0.024532 & 1194.192000 & 119.419200 \\
8.000000 & 7.720486 & 0.089022 & 5677.691000 & 567.769200 \\
12.000000 & 11.417040 & 0.191839 & 13632.240000 & 1363.224000 \\
16.000000 & 15.013690 & 0.335029 & 25047.580000 & 2504.758000 \\
20.000000 & 18.512960 & 0.519991 & 39669.600000 & 3966.960000 \\
24.000000 & 21.913290 & 0.750279 & 57234.630000 & 5723.463000 \\
28.000000 & 25.220760 & 1.026292 & 77550.370000 & 7755.037000 \\
\hline
\end{tabular}

Table 1: Increasing demand rate

\begin{tabular}{rcccl}
\hline \multicolumn{1}{c}{$\mu$} & ER2 & EL & ERP & TRPT \\
\hline 50.000000 & 9.578207 & 0.136292 & 9191.772000 & 919.177200 \\
100.000000 & 9.439519 & 0.152779 & 6925.245000 & 692.524500 \\
150.000000 & 9.531513 & 0.123656 & 7342.198000 & 734.219800 \\
200.000000 & 9.616023 & 0.999907 & 7881.722000 & 788.172200 \\
250.000000 & 9.677223 & 0.083293 & 8315.302000 & 831.530200 \\
300.000000 & 9.722398 & 0.071252 & 8627.994000 & 862.700400 \\
350.000000 & 9.756836 & 0.062171 & 8860.721000 & 886.072100 \\
400.000000 & 9.783290 & 0.055248 & 9109.823000 & 910.982300 \\
\hline
\end{tabular}

Table 2: Increasing mean lead time

\begin{tabular}{clllr}
\hline B & ER2 & EL & ERP & \multicolumn{1}{c}{ TRPT } \\
\hline 10.000000 & 3.918395 & 0.024532 & 1194.192000 & 119.419200 \\
20.000000 & 3.918395 & 0.024532 & 1194.192000 & 59.709590 \\
30.000000 & 3.919132 & 0.024450 & 1203.044000 & 40.101460 \\
40.000000 & 3.918395 & 0.024532 & 1194.192000 & 29.854790 \\
50.000000 & 3.919307 & 0.024306 & 1201.919000 & 24.038370 \\
60.000000 & 3.919132 & 0.024450 & 1203.044000 & 20.050730 \\
70.000000 & 3.919307 & 0.024306 & 1201.919000 & 17.170270 \\
80.000000 & 3.918395 & 0.024532 & 1194.192000 & 14.927400 \\
90.000000 & 3.918395 & 0.024532 & 1194.192000 & 13.268800 \\
\hline
\end{tabular}

Table 3: Increasing repair rate of production system

\begin{tabular}{ccrrr}
\hline $\mathrm{A}$ & ER2 & \multicolumn{1}{c}{ EL } & \multicolumn{1}{c}{ ERP } & \multicolumn{1}{c}{ TRPT } \\
\hline 0.000100 & 3.918395 & 0.024532 & 1194.192000 & 119.419200 \\
0.001100 & 3.885011 & 0.031607 & 74.788610 & 7.478861 \\
0.002100 & 3.860875 & 0.037080 & 30.009070 & 3.000907 \\
0.003100 & 3.840271 & 0.042133 & 16.885130 & 1.688513 \\
0.004100 & 3.824512 & 0.046133 & 11.450830 & 1.145083 \\
0.005100 & 3.811974 & 0.049424 & 8.719021 & 0.871902 \\
0.006100 & 3.801872 & 0.052130 & 7.176444 & 0.717644 \\
0.007100 & 3.793521 & 0.054414 & 6.193297 & 0.619330 \\
0.008100 & 3.786610 & 0.056331 & 5.518878 & 0.551888 \\
0.009100 & 3.780837 & 0.057954 & 5.032046 & 0.503205 \\
\hline
\end{tabular}

Table 4: Increasing failure rate of production system 


\begin{tabular}{cllrr}
\hline$\alpha$ & ER2 & EL & \multicolumn{1}{c}{ ERP } & \multicolumn{1}{c}{ TRPT } \\
\hline 0.005000 & 3.918395 & 0.024532 & 1194.192000 & 119.419200 \\
0.010000 & 3.816794 & 0.050205 & 1712.152000 & 171.215200 \\
0.015000 & 3.779261 & 0.059615 & 2906.625000 & 290.662500 \\
0.020000 & 3.762943 & 0.063705 & 4272.139000 & 427.213900 \\
0.025000 & 3.753937 & 0.065960 & 5734.917000 & 573.491700 \\
0.030000 & 3.748250 & 0.067382 & 7218.313000 & 721.831200 \\
0.035000 & 3.744323 & 0.068365 & 8723.482000 & 872.348300 \\
0.040000 & 3.741594 & 0.069047 & 10221.340000 & 1022.134000 \\
0.045000 & 3.739684 & 0.069525 & 11703.230000 & 1170.32300 \\
0.050000 & 3.738422 & 0.069840 & 13155.550000 & 1315.55500 \\
\hline
\end{tabular}

Table 5: Increasing rate of production

\section{CONCLUSIONS}

A two-component production inventory system is studied, in which one component is produced by the organization itself, and the other by the outside supplier. Various measures of system performance have been obtained analytically, and the results are illustrated numerically. From Table 1 of the numerical illustration, we observe that as $\lambda$ increases, the mean rate of reorder level of product 2 , lost demands, repair of production system, and total repair time increases for a fixed reorder level of product 1. From Table 2, it can be seen that as $\mu$ increases, the mean rate of reorder level 2 decreases, whereas other measures increase with a fixed reorder level of product 1 . Similar observations can be made from the other Tables.

Acknowledgements: The author wishes to thank the referees for their valuable comments.

\section{REFERENCES}

[1] Arbib, C and Marinelli, F, 2004. A p-Median model for Assortment and Trim loss minimization with an application to the glass industry. Unpublished paper.

[2] Arreola-Risa, A, 1996. Integrated multi item production inventory systems. European Journal of Operational Resources, Volume 89, pp 326-340.

[3] Bourland, K E, Powell, S G, and Pyke, D F., 1996. Exploiting timely demand information to reduce inventories. European Journal of Operational Research, Volume 92, pp 239-253.

[4] Cinlar, E, 1975. Introduction to stochastic processes. Prentice Hall.

[5] Raafat, F 1991. Survey of literature on continuously deteriorating inventory models. Journal of Operational Research Society, Volume 2, pp 81-91.

[6] Yadavalli, V S S, Anbazhagan, N, and Arivarignan G, 2004. A two commodity stochastic assembly system with lost sales. Stochastic Analysis and Applications, Volume 22, pp $479-494$. 